\title{
Unanswered Response to Dexmedetomidine and Exaggerated Response to Propofol during Deep Brain Stimulation in Essential Tremor Case
}

\author{
I. S. Yorulmazi ${ }^{*}$, A. U. Esbah ${ }^{2}$, S. Dikici ${ }^{3}$, O. Ozlu1 ${ }^{1}$ U. Er ${ }^{4}$ \\ ${ }^{1}$ Faculty of Medicine Anesthesiology and Intensive Care Depth, Duzce University, Duzce, Turkey \\ ${ }^{2}$ Anesthesiology and Intensive Care Depth, Ataturk Government Hospital, Duzce, Turkey \\ ${ }^{3}$ Faculty of Medicine Neurology Depth, Duzce University, Duzce, Turkey \\ ${ }^{4}$ Faculty of Medicine Neurosurgery Depth, Duzce University, Duzce, Turkey \\ Email: ${ }^{*}$ issekerdtf@gmail.com
}

How to cite this paper: Yorulmazi, I.S., Esbah, A.U., Dikici, S., Ozlu, O. and Er, U. (2017) Unanswered Response to Dexmedetomidine and Exaggerated Response to Propofol during Deep Brain Stimulation in Essential Tremor Case. Open Access Library Journal, 4: e3605.

https://doi.org/10.4236/oalib.1103605

Received: April 14, 2017

Accepted: June 20, 2017

Published: June 23, 2017

Copyright $\odot 2017$ by authors and Open Access Library Inc.

This work is licensed under the Creative Commons Attribution International License (CC BY 4.0).

http://creativecommons.org/licenses/by/4.0/

CC) (i) Open Access

\begin{abstract}
Background: In our case we discussed the sedation made with dexmedetomidine unresponsiveness and exaggerated response to propofol of patients with essential tremor. Case: 75 years old, male, without any co-existing disease, with essential tremor patient, planned deep brain stimulation operation under sedoanalgesia, one week before the operation the patient evaluated and was planned to perform brain magnetic resonance imaging (MRI) under sedation in the MRI unit. We performed sedation with fractional doses of $20 \mathrm{mg}$ propofol than maintained the propofol infusion $0.5-1 \mathrm{mg} / \mathrm{kg} /$ hour. At the 20th minute the propofol infusion was stopped on the dropped of the patient's blood pressure at 50/35 mmHg. After $20 \mathrm{mg}$ efedrin was given intravenously, blood pressure was achieved to the basal levels in one minute. One week after we performed MRI and we gave only half dose of first time. Sleeping pattern analysis for obstructive sleep apnea or sleeping disorders was done for this patient. On the DBS day we decided to perform the procedure with dexmedetomidine. Initial bispectral index values 98\% - 99\% (BIS aspect). After 20 minute neither BIS values, nor Ramsey changes. We maintained high doses dexmedetomidine but it didn't worked, so we turned to propofol on 30th minute and after we performed $10 \mathrm{mg}$ propofol, BIS values was $85 \%$ - $88 \%$ throughout the operation. We gave $40-50 \mathrm{mg}$ propofol totally throughout the procedure and RSS was 3 - 4. Discussion: Unresponsiveness of dexmedetomidine that we faced in our case may be by neurodegeneration of locus coeruleus and we could explain this exaggerated response to propofol of this patient on GABA receptor increased intensity.
\end{abstract}




\section{Subject Areas}

Clinical Trials

\section{Keywords}

Dexmedetomidine, Deep Brain Stimulation, Sedoanalgesia, Essential Tremor, Anesthesia

\section{Introduction}

Deep brain stimulation can be applied under sedation for surgery in the treatment of patients with essential tremor. It is not known exactly why the effect on the GABA system and locus cereous responses can occur against different therapeutic agents in these patients.

\section{Case}

75 years old, male, without any co-existing disease, with essential tremor patient, planned deep brain stimulation operation under sedoanalgesia, one week before the operation the patient evaluated. There wasn't found any cardiovascular or respiratory and endocrine system disease on physical examination and past medical history. Brain magnetic resonance imaging was planned under sedoanalgesia in the MR unit. We planned to perform sedation with propofol fractional doses of 20 mg than when he has reached the Ramsey 3 - 4 levels, maintained the propofol infusion $0.5-1 \mathrm{mg} / \mathrm{kg} / \mathrm{hour}$. His initial blood pressure was $110-60 \mathrm{mmHg}$, health rate 60 beat/hour. We made a standard monitorisation and administered two time $20 \mathrm{mg}$ propofol dose within 3 minute interval and maintained dose at 0.5 $\mathrm{mg} / \mathrm{kg} / \mathrm{min}$. After 40 th minute the patient fully sedated and became ramsey 4 and was began to snoring. The pulse oximeter values reduced at 92\% - 90\%-89\% continuously. We placed an airway and increased the SpO2 level 93\%. On 20th minute the patient blood pressure suddenly dropped $50 / 35 \mathrm{mmHg}$ and we stopped the propofol. Efedrin was given and blood pressure was achieved to the basal levels immediately. After 1 week we tried to brain magnetic resonance imaging and I gave the half dose of which was given the first time. Everything was ok and we finished the procedure and we recommend to the surgent and neurologist that must make a sleeping pattern analysis for obstructive sleep apne or sleeping disorders for this patient. On the DBS day we decided to perform procedure with dexmedetomidine. We were administered the loading dose and maintained dose. The patient's initial bispectral index values 98\% - 99\% (BIS aspect). After 20 minute neither BIS values, nor Ramsey changes. We started to give very high doses dexmedetomidine but it didn't worked so we decided to turn propofol on 30th minute again and after the administration of the $10 \mathrm{mg}$ propofol, BIS values was $85 \%$ - $88 \%$ throughout the operation. We gave 40 - $50 \mathrm{mg}$ propofol totally throughout the procedure and Ramsey Sedation Scale went on level 3 - 4. At the end of the operation the patient was transferred to the neurosurgery service that 
fully awake, cooperate, with spontaneous breathing, cardiovascular and hemodynamic stabilization and without neurologic complication.

\section{Discussion}

Essential tremor is unknown exactly: which is a neurodegenerative disease group treated with Gamma-Aminobutyric acid (GABA) receptor agonists, antiepileptic drugs, gabapentin, benzodiazepines and deep brain stimulation techniques. Sedative agents can be used during deep brain stimulation (DBS) placement procedures. Despite of both propofol and dexmedetomidine providing the same clinically result, when we evaluated the electroencephalographic (EEG) changes, we saw almost the similar activity suppression pattern of this two different drugs. Propofol is an agonist on Gamma-Aminobutyric acid (GABA) receptors and dexmedetomidine is an alfa 2 adrenoreceptor agonists [1].

We explained the dexmedetomidine unresponsiveness first with his sleeping disorders, because he has got severe sleeping disorder (confirmed with sleep lab) and reported severe neuronal damage in locus coeruleus region in this group of patients. Also dexmedetomidine affects locus coeruleus. But the second question is that the cause of this exaggerated responses of the brain for the propofol in this patient. And we started the search on this fact. It seems that propofol decreases the connectivity especially thalamus, but it also increases the connectivity within the pons of the brainstem during propofol-induced mild sedation [2] [3]. The second view point shown by Yağar and his colleagues. They investigate the association between the effect of alfa 2A-Adrenergic Receptor (ADRA2A) C-1291G gene polymorphism and clinical effects of dexmedetomidine on one hundred and ten patients undergoing coronary artery surgery. They showed that there was a weak effect of ADRA2A C1291G gene polymorphism in response to dexmedetomidine [4]. Alfa 2A-Adrenergic Receptor (ADRA2A) gene is highly polymorphic [5]. G allele carriers were more sedated than others with dexmedetomidine [4]. Propofol coordinated frontal EEG alpha oscillations and asynchronous thalamocortical slow oscillations similar to the dexmedetomidine showed slow oscillations and dex spindles called' spindle like activity'. However, in terms of behavioral and clinical characteristics of these two drugs, it shows different characteristics [6] [7].

When performed functional MRI imaging in healthy people under propofol sedation which reduces activity in the pons, thalamus and brain stem has been shown to increase the activity. That seems to be the key component of a break in the thalamocortical communication during propofol sedation [8] [9].

The roads leading from the thalamus to the cortex are formed by major GABAergic inhibitory effects. Positron emission tomography studies done to suggest that propofol is associated with a decrease in neuronal activity in the thalamus of the anesthetic-induced unconsciousness [10]. Propofol showed sedation at low doses, at high doses constitute unconsciousness. Dexmedetomidineis create nonREM like sleep in a short-term period of slow oscillation. Propofol is while creating a similar pattern is observed in more prolonged OFF periods [11]. 
GABA hypothesis in essential tremor patients have been proposed. GABAergic system is especially located on the cerebellum. This hypothesis leading to the loss of cerebellar Purkinje cells in cerebellar neuron degeneration low GABA system activity, disinhibition of pacemaker activity of cerebellar neurons, increased activity of thalamus and rhythmic activity of thalamocortical circuit that leads tremor [12].

A slight increase in CSF and serum concentrations of glutamate in a study by way of example, reduced levels of GABA, glycine and serine low levels have been identified. It also strengthened the argument that patients with ET have GABAergic dysfunction [13].

Positron Emission Tomographic scans which have done with $\left[\mathrm{C}^{11}\right]$ flumazenil on ET patients, showed that there was a lateral premotor cortex abnormality on venterolateral thalamus in the $\mathrm{GABA}_{\mathrm{A}}$ receptor binding region. $\mathrm{GABA}_{\mathrm{A}}$ receptor binding abnormally increased in cerebellar-thalamic input path was also determined [14].

In our case, we observed very low dose ( $40 \mathrm{mg}$ of propofol, 2.5 hours operation time) despite the effective tremor control and adequate level of sedation (Ramsey 3 - 4, BIS values $80 \%$ - 92\%) (Figure 1) was provided on the one hand

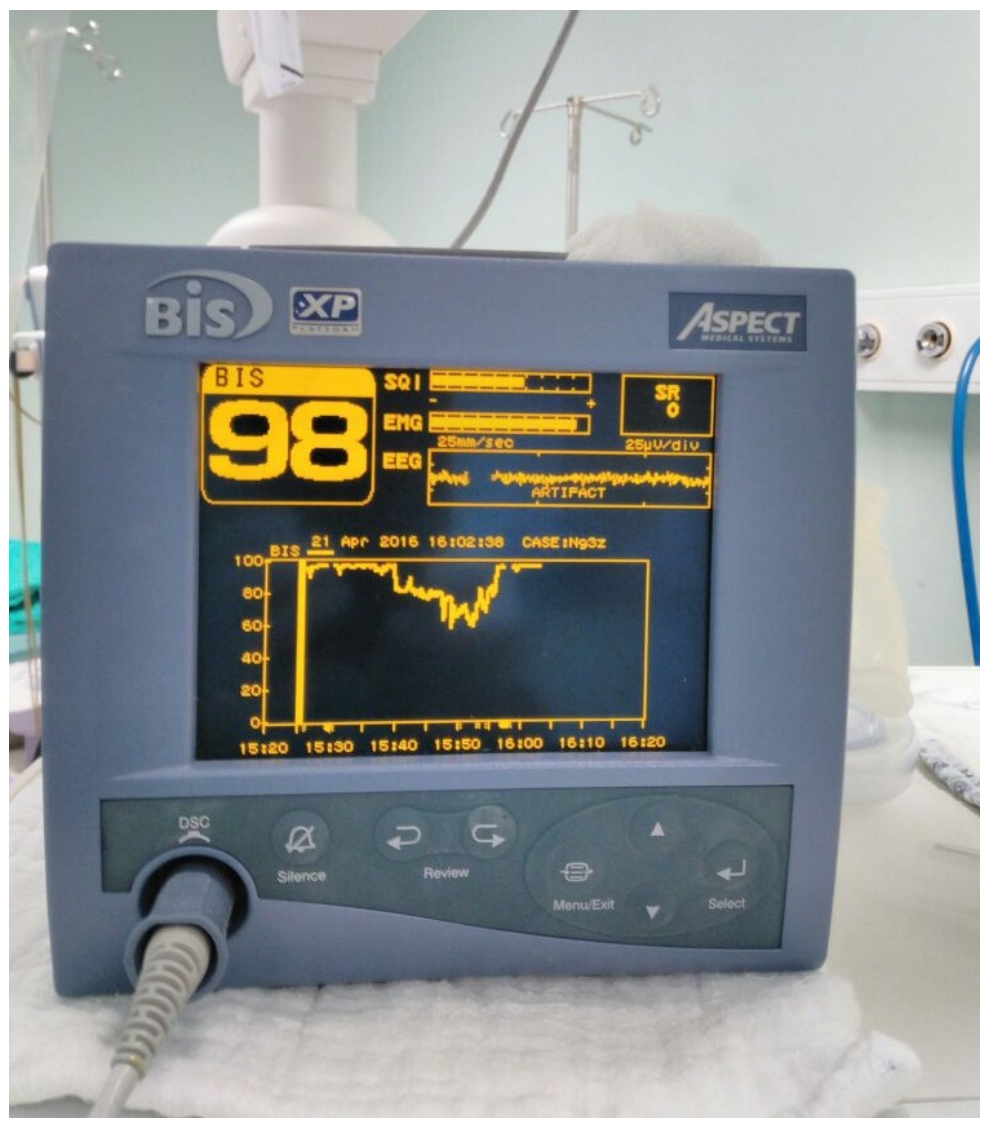

Figure 1. Shows bispectral index values and graph throughout the deep brain stimulation surgery procedure of the patient. Dexmedetomidine unresponsiveness has seen as high levels of bispectral index at first 20 minute of the procedure. 
supports of GABAergic hypothesis, increased binding to $\mathrm{GABA}_{\mathrm{A}}$ receptor in response to propofol.

\section{References}

[1] Kaskinoro, K., Maksimow, A., Georgiadis, S., Langsjö, J. and Scheinin, H. (2015) Electroencephalogram Reactivity to Verbal Command after Dexmedetomidin, Propofol and Sevoflurane-İnduced Unresponsiviness. Anaesthesia, 70, 190-204. https://doi.org/10.1111/anae.12868

[2] Zhang, H., Wang, W., Zhao, Z., Ge, Y., Zhang, J., Yu, D., Chai, W., Wu, S. and Xu, L. (2010) The Action Sites of Propofol in the Normal Human Brain Revealed by Functional Magnetic Resonance. The Anatomical Record, 293, 1985-1990. https://doi.org/10.1002/ar.21289

[3] Song, X.X. and Yu, B.W. (2015) Anesthetic Effects of Propofol in the Healthy Human Brain: Functional İmaging Evidence. Journal of Anesthesia, 29, 279-288. https://doi.org/10.1007/s00540-014-1889-4

[4] Yagar, S., Yavas, S. and Karahalil, B. (2011) The Role of the ADRA2A C1291G Genetic Polymorphismin Response to Dexmedetomidine on Patients Undergoing Coronaryartery Surgery. Molecular Biology Reports, 38, 3383-3389. https://doi.org/10.1007/s11033-010-0446-y

[5] Belfer, I., Buzas, B., Hipp, H., Philips, G., Taunman, J., Loricz, I., et al. (2005) Haplotyped-Based Analysis of Alpha 2A, 2B, and 2C Adrenergic Receptor Genes Captures İnformation on Commonfunctional Loci at Each Gene. Journal of Human Genetics, 50, 12-20. https://doi.org/10.1007/s10038-004-0211-y

[6] Huupponen, E., Maksimow, A., Lapinlampi, P., Sarkela, M., Saastamoinen, A., Snapir, A., Scheinin, H., Scheinin, M., Merilainen, P., Himanen, S.L. and Jaaskelainen, S. (2008) Electroencephalogram Spindle Activity during Dexmedeto- midine Sedation and Physiological Sleep. Acta Anaesthesiologica Scandinavica, 52, 289-294. https://doi.org/10.1111/j.1399-6576.2007.01537.x

[7] Aksu, R., Kumandas, S., Akin, A., Bicer, C., Gumus, H., Guler, G., Per, H., Bayram, A. and Boyaci, A. (2011) The Comparison of the Effects of Dexmedetomidine and Midazolam Sedation on Electroencephalography in Pediatric Patients with Febrile Convulsion. Pediatric Anesthesia, 21, 373-378. https://doi.org/10.1111/j.1460-9592.2010.03516.x

[8] Gili, T., Saxena, N., Diukova, A., Murphy, K., Hall, J.E. and Wise, R.G. (2013) The Thalamus and Brainstem Act as Key Hubs in Alterations of Human Brain Network Connectivity Induced by Mild Propofol Sedation. Journal of Neuroscience, 33, 4024-4031. https://doi.org/10.1523/JNEUROSCI.3480-12.2013

[9] Bonhomme, V., Fiset, P., Meuret, P., Backman, S., Plourde, G., et al. (2001) Propofol Anesthesia and Cerebral Blood Flow Changes Elicited by Vibrotactile Stimulation: A Positron Emission Tomography Study. Journal of Neuroscience, 85, 1299-1308.

[10] Jones, E.G. (2002) Thalamic Circuitry and Thalamocortical Synchrony. Philosophical Transactions of the Royal Society of London. Series B, 357, 1659-1673. https://doi.org/10.1098/rstb.2002.1168

[11] Lewis, L.D., Weiner, V.S., Mukamel, E.A., Donoghue, J.A., Eskandar, E.N., Madsen, J.R., Anderson, W.S., Hochberg, L.R., Cash, S.S., Brown, E.N. and Purdon, P.L. (2012) Rapid Fragmentation of Neuronal Networks at the Onset of Propofol- Induced Unconsciousness. Proceedings of the National Academy of Sciences of the United States of America, 109, E3377-E3386. https://doi.org/10.1073/pnas.1210907109 
[12] Gironell, A. (2014) The GABA Hypothesis in Essential Tremor: Lights and Shadows. Tremor and Other Hyperkinetic Movements, 4, 254.

[13] Mally, J., Baranyi, M. and Vizi, E.S. (1996) Change in the Concentrations of Amino Acids in CSF and Serum of Patients with Essential Tremor. Journal of Neural Transmission, 103, 555-560. https://doi.org/10.1007/BF01273153

[14] Gironell, A., Figueiras, F.P., Pagonabarraga, J., Herance, J.R., Pascual-Sedano, B., Trampal, C. and Gispert, J.D. (2012) Gaba and Serotonin Molecular Neuroimaging in Essential Tremor: A Clinical Correlation Study. Parkinsonism \& Related Disorders, 18, 876-880. https://doi.org/10.1016/j.parkreldis.2012.04.024

Submit or recommend next manuscript to OALib Journal and we will provide best service for you:

- Publication frequency: Monthly

- 9 subject areas of science, technology and medicine

- Fair and rigorous peer-review system

- Fast publication process

- Article promotion in various social networking sites (LinkedIn, Facebook, Twitter, etc.)

- Maximum dissemination of your research work

Submit Your Paper Online: Click Here to Submit

Or Contact service@oalib.com 